\title{
Mobilizing a Public Health Response: Supporting the Perinatal Needs of New Yorkers During the COVID-19 Pandemic
}

\author{
Elizabeth Claudio ${ }^{1}$. Julia Donahue ${ }^{2} \cdot$ P. Mimi Niles ${ }^{3} \cdot$ Anna Pirsch $^{2} \cdot$ Patricia Ramos $^{4}$. llish Neely ${ }^{5}$. \\ Regina Conceiçaõ ${ }^{6} \cdot$ Mary-Powel Thomas $^{7} \cdot$ Tayisha St Vil $^{8} \cdot$ Deborah Kaplan $^{8}$
}

Published online: 1 August 2020

(c) Springer Science+Business Media, LLC, part of Springer Nature 2020

\section{Background/Context}

In March 2020 New York City became the epicenter of the COVID-19 pandemic. By mid-March, nearly all the 6500 employees of the New York City Department of Health and Mental Hygiene (NYC Health Department), the largest public health department in the nation, began working from home. Reports quickly emerged of the immense stress on hospital and public health systems, with critical personal protective equipment (PPE) shortages, lack of testing capacity, and strained emergency response. At the same time, NYC Health Department staff were hearing daily updates

Deborah Kaplan

deborahlenorekaplan@gmail.com

Elizabeth Claudio

eclaudi1@ health.nyc.gov

Julia Donahue

Julia.donahue@gmail.com

P. Mimi Niles

paulomi.niles@ubc.ca

Anna Pirsch

annapirsch@gmail.com

Patricia Ramos

pramos@health.nyc.gov

Ilish Neely

ineely@health.nyc.gov

Regina Conceiçã̃

rconceicao@health.nyc.gov

Mary-Powel Thomas

mthomas7@health.nyc.gov

Tayisha St Vil

Tayisha.Stvil@gmail.com

1 Newborn Home Visiting Program, Traditional Model, Bureau of Maternal, Infant and Reproductive Health, Division of Family and Child Health, NYC Department of Health and Mental Hygiene, New York, USA about a growing number of COVID-19 cases and deaths among New Yorkers. Agency home visiting staff learned that one of their colleagues had died from COVID-19, and two others became ill, with one requiring hospitalization. While in mourning for our colleagues and the city, it became apparent that, once again, Black and Brown people were disproportionately impacted by a health condition; in NYC the age adjusted rate of hospitalization and death among Black/African-American and Hispanic/Latinx people was twice as high as among White and Asian/Pacific Islander people.(NYC Health 2020a) Meanwhile the NYC Health Department continued to do its work serving pregnant and

2 NYC Nurse-Family Partnership, Bureau of Maternal, Infant and Reproductive Health, Division of Family and Child Health, NYC Department of Health and Mental Hygiene, New York, USA

3 Woodhull Medical Center, NYC Health + Hospitals, New York, USA

4 Newborn Home Visiting Program, Shelter Initiative Model, Bureau of Maternal, Infant and Reproductive Health, Division of Family and Child Health, NYC Department of Health and Mental Hygiene, New York, USA

5 Bronx Neighborhood Health Action Center, Center for Health Equity and Community Wellness, NYC Department of Health and Mental Hygiene, New York, USA

6 By My Side Birth Support Program, Healthy Start Brooklyn, Center for Health Equity and Community Wellness, NYC Department of Health and Mental Hygiene, New York, USA

7 Healthy Start Brooklyn, Center for Health Equity and Community Wellness, NYC Department of Health and Mental Hygiene, New York, USA

8 Bureau of Maternal, Infant and Reproductive Health, Division of Family and Child Health, NYC Department of Health and Mental Hygiene, New York, USA 
parenting families, staying focused on the most marginalized New Yorkers, predominantly Black and Brown people residing in neighborhoods that have been intentionally disinvested in for decades due to systemic racism, resulting in high rates of poverty, poor housing, unemployment and chronic stress, and limited access to healthy and affordable food, all factors that jeopardize people's health. We were tasked with communicating public health messages of safety and prevention; social distancing, universal precautions, vigilant hand hygiene, and staying home were key. We also continued our work to build the Maternity Hospital Quality Improvement Network, a multifaceted hospital and community-based partnership with specific efforts to tackle institutional racism and assure safe and respectful perinatal care for all.(NYC Health 2018, 2020c).

Giving birth in New York City has long been plagued with racial inequities in maternal mortality, with Black women shockingly eight times more likely to die of a pregnancy-related cause than white women (New York City Department of Health and Mental Hygiene 2020) and three times more likely to have a life-threatening complication related to pregnancy. A core agency mission is to address the root causes of these disparities, structural racism, and gender oppression. Our hospitals are some of the most racially segregated in the nation.(Minkoff and Chiasson 2017) At the public hospitals and poorly resourced private hospitals, $83 \%$ of live births are paid for by Medicaid, in contrast to the highly resourced private and academic medical centers, where just $30 \%$ of live births are paid for by Medicaid. ${ }^{1,2}$ Over $98 \%$ of the approximately 120,000 births in NYC each year occur in one of the 38 hospitals that provide maternity care. Though the demand for out of hospital births increased during the pandemic, there are only two birthing centers (one opened during the pandemic), and limited use of midwives. ${ }^{3}$ Where midwives do attend childbirth, they are not well integrated, and the Medicaid reimbursement rate is lower for a vaginal birth attended by a midwife than by a physician. These factors are compounded by inadequate funding for public health. Overall public health spending by the United States federal government, which mostly goes to state and local health departments, decreased $9.3 \%$ from 2008 to 2014.(Himmelstein and Woolhandler 2016) The Centers for Disease Control and Prevention (CDC) Public Health Emergency Preparedness (PHEP) Cooperative Agreement,

\footnotetext{
${ }^{1}$ Source: NYC DOHMH Bureau of Vital Statistics Limited Use Birth Data for 2018.

${ }^{2}$ In NYC, Medicaid covers all people who are pregnant up to $200 \%$ of poverty including people who are undocumented (although this insurance ends for the mother about 8 weeks following childbirth if she is undocumented).

${ }^{3}$ One important exception are three public hospitals (Health + Hospitals) where midwifery services are integrated into perinatal services.
}

the main source of funding for emergency preparedness and response by health departments, was cut by about $\$ 400$ million from 2003 to 2020 despite the fact that public health emergencies increased in severity and frequency during that same time period.(Trust for America's Health 2020).

Little attention was paid to the burdens being felt by pregnant and parenting people at the beginning of the COVID19 pandemic. How could a person stay out of the hospital if they needed to get a necessary prenatal exam? How would they travel? Who would be with them during labor? It quickly became apparent that the needs of this population were an afterthought. In early April, we began to hear reports of parents having difficulty finding infant formula, and some hospitals not allowing birthing people to have even one support person with them during childbirth.(Bobrow 2020) People were afraid to give birth in the hospital for fear of contracting COVID-19 and were desperately seeking alternatives, sometimes pleading with the birthing center or home birth midwives to add them to their caseload; these midwives usually had to decline due to full caseloads and because it would be unsafe to enroll a new client in their last trimester of pregnancy.(de Freytas-Tamura 2020) Despite these challenges, we were able to mobilize the various work we do throughout the city to care for the diverse needs of New Yorkers. We assembled a group of employees to share their real time experiences of providing care, services and programming to directly address the needs of pregnant and parenting New Yorkers during COVID-19. Here are their stories.

\section{A Midwife in the Middle: P. Mimi Niles, PhD, MPH, CNM}

I remember in my bones, the feeling of being a midwife during Sandy. It was chaos in darkness. And now here I stand six years later, stepping onto an empty subway train headed into another kind of storm, with a similar feeling of being untethered and unsure. In those first few weeks, we were not prepared as we tried to balance caring for our patients and caring for ourselves and each other while knowing very little about this virus.

Those early weeks were like a storm amidst the shifting guidelines, causing anxiety for many of us. What we quickly realized, walking by mobile refrigerated morgues, hearing the sirens, listening to the constant overhead pages for respiratory therapists and code blue (which means someone is experiencing a life-threatening medical emergency) was that we were figuring out how to care for people with a virus that had been silently spreading in our communities for weeks, possibly months. We also knew that we were caring for the communities most ravaged by this virus, as we care for the Black and brown people that hold this city up-the 
bus drivers, the store clerks, the home health aides, these are our patients. We are essential workers taking care of other essential workers.

And while the community and hospital were shrouded in death and illness, we continued to do our best to maintain the sanctity and joy of welcoming new life and new families. Despite the fact that babies would keep being born, mothers and babies were forgotten. After the second week, I remember calling Dr. Kaplan at the NYC Health Department in desperation. As I was transitioning from working midwife and blossoming researcher, it became clear that we needed to build bridges between providers at the frontline and our public health colleagues in order to develop a comprehensive care plan to protect both the healthcare workers and the women and families we all serve.

\section{Centering Black Lives: Tayisha St Vil, MPH, CLC}

Before March 20, 2020, eliminating the racial inequities in maternal mortality and morbidity is where my team primarily focused its efforts. As a Black woman of reproductive age, I do this work with full awareness of all the statistics that remind me that Black people consistently suffer the worst outcomes. I do this work wondering if I will become a statistic.

After March 20th, a team of dedicated public health servants at the NYC Health Department rallied to address the changing needs of pregnant and postpartum people. Within days, we rapidly stood up the agency's COVID-19 Perinatal Task Force with the goal to promote the best possible birthing experience and birth outcomes while mitigating the risk of COVID-19 for people giving birth, their newborns, their families, and providers. We developed guidance for people who are pregnant and/or caring for infants, and for doulas. (NYC Health 2020b).

Everything feels like the Twilight Zone since March 20th. Going through this dual pandemic of COVID-19 and systemic racism is exhausting, to say the least. I reminisce of the "before" times but it's been long overdue for the veil to be lifted-and for that reason I am grateful for the chaos. Even as I respond to this pandemic, I live in fear of contracting COVID-19, and I worry for my own family who all have the comorbidities that put them at risk. As a Black Queer woman, I am acutely aware that, for many, disrespect, disregard and dehumanization are common features of birthing while Black. The deaths of Breonna Taylor, Tony McDade, Ahmaud Arbery, George Floyd and countless others show how the dehumanization of Black people pervades all parts of our lives and communities. My work and passion are to serve birthing people and their families. I am proud to be a part of a team that is doing work to protect, love and care for Black families in New York City.

\section{Supporting Families, Supporting Doulas: Mary-Powel Thomas, BA, FDC}

The night before we started working remotely, I sent an email to my team at Healthy Start Brooklyn about the need to adapt our services for the virtual space. We had been training doulas in our By My Side Birth Support Program on providing "comforting touch" during childbirth, but now reports of hospital restrictions meant doulas might not be able to attend births at all. In response, colleagues and I drafted a letter to obstetric chairs, highlighting the essential role that doulas play in positive birth outcomes - especially for clients who struggle against income inequality and racism.

One aspect of the pandemic that no one could plan for was how fast policy and practice were changing. Before we could send the letter on the key role doulas can play, New York State Governor Andrew Cuomo issued an executive order requiring hospitals to only allow one support person to be with the person giving birth. Since many patients had both a partner and a doula, most doulas were essentially barred from the labor room. Though questions remained, with so much about the virus we didn't understand, we developed a safe practice guide for doulas to serve their clients while protecting themselves and others. The documents included advice on providing virtual support.(NYC Health 2020b) And then the restrictive visitation policy changed from only one support person to considering the doula to be an essential member of the birth team. It was a complicated victory, with many NYC doulas worried about contracting and/or spreading the virus. As one said, "At first I thought, 'How dare they block me from my clients!' Now I'm like, 'Ehh, maybe I should just stay home."”.

Through it all, Healthy Start Brooklyn focused on its mission to provide education and support for pregnant people and new parents. Quarantining meant increasing levels of emotional and financial stress for these families. We shipped diapers and portable playards to clients in need, and we publicized information about food distribution resources, as well as job-hunting resources. Our mental health clinician was busy helping clients through depression, anxiety, and intimate partner violence. We provided PPE for doulas who attended births. And through this pandemic, the value of our work was made abundantly clear.

\section{Bearing Witness: Anna Pirsch MS, RN-BC, CLC}

At the height of the outbreak, there were so many questions and very few answers. I will share the story of one of my clients, who I had been working with for close to two years. 
She was struggling with the isolation in a less-than-ideal homeless shelter placement. I could hear the sadness in her voice as she let go of her dream of having an in-person high school graduation, was forced to have her son's first birthday alone in the shelter, and grappled with the decision to leave the city. She ended up leaving the city and I couldn't help her there; the only thing I could do was find resources and continue to talk to her. I realized more than ever that my work was not just to support her parenting and the development of her son, it was also to listen and hold a space for us to explore feelings about her situation. Our time together also offered pockets of joy, singing "Baby Shark" together on a video call or an emoji filled text exchange. Part of my work is to bear witness to whatever situation my clients are facing.

It is my privilege to be invited into the heart and homes of my clients. As a public health nurse with the Nurse-Family Partnership (NFP) program, I saw how we have been able to remain connected through this pandemic, virtually and spiritually, and even now as we enter into the next phase of this pandemic, complicated by protests surrounding racial inequality and unjust death in our nation. We can see the systemic issues arise and worsen, and although we as nurses struggle to frame this, struggle to see what will come next, we will continue to bear witness, and seek to find the vein of gold in the boulder of challenges our clients may face.

\section{Building Hope Online: Ilish Neely, MPH, FDC, CLC}

On Monday March 16th, casual conversations about weekend plans were replaced with an energy of confusion and fear. Though fuzzy, I recall a chill-inducing email from human resources suggesting we should update our beneficiaries. I spent the first two months of the pandemic obsessed with staying healthy. Together, we would learn case by case, the havoc created by this invisible virus that was claiming the lives of hundreds of New Yorkers a day while the constant sounds of sirens became the soundtrack of the city.

Babies would not wait to be born. It became imperative that the work of the Family Wellness Suites, a place-based maternal health intervention, pivot as the families looked to us as public health advocates for answers. The Family Wellness Suite Team worked diligently for weeks to launch $90 \%$ of our programming online. The traditional obstacles such as obtaining carfare and childcare, often culprits in many families' inability to join our on-site offerings, were eliminated. We realized the significance of bringing our health education services directly into people's homes. We would use telehealth to teach childbirth education, sexual health education for teenagers, newborn care and even tenant rights. The team also learned of the micro- and macrotraumas families were experiencing due to the pandemic, such as job loss, disruption to benefits and food insecurity, which motivated us to offer programming that would holistically support them.

It was exciting to reach beyond our designated catchment areas and collectively reimagine the value and influence of our work. As a result, we are still birthing new ideas. We've created expedited plans to distribute car seats and portable cribs to New Yorkers in need, while providing virtual safe sleep and infant safety classes. While we have lost the inperson contact that many of us thrive on, we are committed to preserving the integrity of the services we provide and try to be a source of normalcy during an abnormal time.

\section{Preparing for the Worst While Doing Our Best: Elizabeth Claudio, MA, CLC}

On my last day at my office, I remember packing up as I prepared for the unknown. During all of this I was thinking about my health and how I needed to protect my family, while also thinking of my clients and future clients. I knew babies were being born and families were also preparing to protect themselves, but how was I going to reach these families?

I am a community health specialist providing home visits through the Newborn Home Visiting Program to families living in neighborhoods that have high infant mortality rates, a program that includes breastfeeding support, environmental assessments, safe sleep and other education, and cribs for families without a safe place for their baby to sleep. Usually, I recruit mothers from two local hospitals where I invite them to participate in the program. One mother, whose story I cannot forget, breastfed her baby for two to three days and then stopped. The client's father had passed away from COVID-19 the same week her baby was born. She lived with her dad and her grief and stress overwhelmed her to the point where she believed she stopped producing milk and her motivation to breastfeed was gone. I was concerned about her mental health and offered to connect her to mental health support services, which she declined. It saddened me to hear this because I lost someone due to COVID-19 as well, and I found counseling was helpful for my family in coping with our loss.

Normally, we recruit families directly at the hospital. Due to the pandemic, we went from contacting families two days after being discharged to waiting to receive their contact information two to four weeks after birth. In interview after interview, I realized that some mothers started out breastfeeding and either stopped and switched to exclusive formula feeding or they stated that their milk supply had decreased. I wish I would have been there in the early days, to encourage my client to breastfeed and to support her through the grief 
of losing her father because I wonder if it would have made a difference. These are the stories that will stay with me.

\section{Finding Community Partners: Julia Donahue, MS, APRN, FNP-BC, CLC}

At the start of the pandemic I knew my nursing practice was about to change dramatically. Our team of public health nurses quickly realized we were learning alongside our clients to figure out what worked. Paula, ${ }^{4}$ a Spanish-speaking Garifuna woman who fled violence in Honduras, was pregnant and living in a family shelter. She enrolled a month before the shelter-in-place orders. After swimming across the border from Mexico, she was held by Immigration and Customs Enforcement (ICE) in a detention center for several weeks until filing for asylum. Paula was physically and socially isolated. She spoke to her mother daily when she had cell phone service, but she did not have a community and the baby's father was working in Illinois without a reliable phone. I referred Paula to community organizations and services during our first visits. Due to her immigration status, she was able to apply for the Special Supplemental Nutrition Program for Women, Infants, and Children (WIC) but did not qualify for other programs. I connected her to church-based food pantries, mental health support, and a labor support doula.

As a public health nurse, I am constantly trying to connect clients with the constellation of community initiatives that exist in the city. Unfortunately, the search for services became acute during the pandemic. Thinking about Paula, I would lie in my bed unable to sleep, scrolling through mutual aid groups for programs that might help. Our NYC Health Department email was flooded with messages from fellow nurses sharing new services they had similarly found. Through Facebook, I found a group that delivers food to Bronx residents that Paula could access. I connected her with Bronx (Re)Birth and Progress, a Black-centered organization that delivers diapers and formula and provides traumainformed perinatal support. In addition, the NFP received a grant to help pay for cell phones for clients so I was able to secure a reliable phone for Paula.

As of today, Paula and her baby (whom I have only seen in photos) are safe and healthy, in part thanks to the grassroots efforts of local organizations. As we mourn the statistics showing the toll this pandemic has taken on Black and Latinx communities, we should have predicted that the most marginalized New Yorkers would be the most harmed. I hope we remember that behind those numbers are people like Paula.

\footnotetext{
${ }^{4}$ Not her real name.
}

\section{Virtual Home Visits for Sheltered Families: Patricia Ramos, MPH, CLC}

When we received the news that New York was given the order to shelter in place in mid-March due to the pandemic, I was home sick with a confirmed case of COVID-19. I was completely isolated, drenched in fear of the unknown.

I supervise a group of public health advisors that conduct home visits to new families. Our newborn home visiting program, designed to support families residing in shelters overseen by the NYC Department of Homeless Services (DHS) would need to do online and phone visits. My team visits families all over the Bronx, the borough with the highest number of COVID-19 related cases, hospitalizations and deaths.

Even as I sat in my small apartment in Hamilton Heights, I reflected on how blessed I was to be able to isolate myself from my son. I know that for families residing in shelters, isolation is not an option. Most units are like studios, and others are just a single room where you don't have access to your own kitchen. By the end of March, I returned to work. Many of our staff, including myself, did not have laptops, or had limited internet service. Many of us also faced the challenge of trying to balance work life with family life. We found that calling our clients on the phone was often the best way to contact them.

What was clear to us, as community health workers, was that the families we support have long faced systemic barriers. Prior to the pandemic, access to resources, food, housing and employment were always important. For families residing in shelters in the Bronx, housing issues such as mold and pest infestations are constant worries. During the pandemic, these parents also had to worry about getting sick, not having access to formula or even baby wipes, adding layers of stress. Every day we do our best to provide information on resources, but the most difficult families to assist are undocumented families who do not qualify for food stamps or rental assistance, leaving them highly vulnerable. Our hope for the program is to provide people with a helpful and supportive presence so that every mother can do their best to care for their newborn.

\section{A System Under Stress-Being Pregnant During COVID-19: Regina M. Conceiçaõ, BA, CD, CPD, CLC, FDC}

In the beginning of March, I returned to work after a beach trip feeling rejuvenated and refreshed only to be met with a palpable sense of urgency. Things were happening lightning fast. As a doula coordinator for the By My Side Birth Support Program in Brooklyn, I began to witness the sudden 
drop in referrals. Our partners were no longer going into the waiting rooms or conducting outreach and recruitment for doula support, childbirth education, newborn care, and infant safety and CPR classes. Clients started to report that their prenatal appointments were being canceled and their anxiety levels went through the roof. Many clients sat with the constraints of the pandemic and the recent media coverage of the Black maternal death of Amber Rose Isaac amidst a stream of racist actions that were being reported. These events compounded pregnant people's anxiety, worry, and angst. I personally lost two people due to COVID-19. One night I received a call from a former client begging me to not forget her kids if she dies. Her husband, an MTA worker, was diagnosed with COVID-19. One of her children was living with a compromised immune system and her elderly in-laws all had co-morbidities. Seven people were living in a two-bedroom apartment trying hard to practice social distancing and isolation. Tears began to stream down my face, and I promised my client that night I would not forget her. For nearly two weeks I checked on my client daily and as of today they are well.

The COVID-19 pandemic has taught us that we need to create better systems of care and social support for pregnant and parenting people, systems that can withstand the stress of any disaster. This may include creating prenatal care kits that contain a blood pressure cuff, disposable measuring tape, urine and glucose strip tests, and universal telehealth access for all. It also became clear that the lack of access to the midwifery model of care for all pregnant people meant that few had access to homebirths and birthing center care, leaving them to navigate a strained system. My hope is that we always center the needs of parents, children and families as they are the backbone of our communities. It is through their resiliency and toughness that they survive despite the systemic racism and injustice that we must face every day.

\section{Conclusion}

COVID-19 has exacerbated longstanding racial and ethnic inequities in perinatal outcomes, rooted in structural racism with the intentional, systematic disinvestment in Black and brown communities, and policies supporting hospital segregation and inequitable distribution of resources to hospitals serving Black, brown and low-income people. As the above stories illustrate, we have been flexible and creative in adapting in this unprecedented time, worsened by the decades long underfunding of public health nationally.(Trust for
America's Health 2020) Moving forward, we must advocate to center and adequately fund services for people who are giving birth and people caring for newborns. This capacity must be built into future emergency responses, so that it is not an afterthought. What we have seen and experienced during the pandemic makes clearer than ever the need to transform perinatal care to meet all people's needs, including full integration of midwives with power-sharing in the provision of care, support for non-hospital births, doula support as an option for all, and community participation in planning for and making these changes.

\section{Reference}

Bobrow, E. (2020). A chaotic week for pregnant women in New York city. The New Yorker. Retrieved June 10, 2020, from https://www. newyorker.com/science/medical-dispatch/a-chaotic-week-forpregnant-women-in-new-york-city.

de Freytas-Tamura, K. (2020). Pregnant and scared of 'Covid Hospitals,' they're giving birth at home. The New York Times. Retrieved June 10, 2020, from https://www.nytimes.com/2020/04/21/nyreg ion/coronavirus-home-births.html.

Himmelstein, D. U., \& Woolhandler, S. (2016). Public health's falling share of US health spending. American Journal of Public Health, $106(1), 56-57$.

Minkoff, H., \& Chiasson, M. A. (2017). When choosing a hospital can be fatal. Crain's New York Business. Retrieved June 6, 2020, from https://www.crainsnewyork.com/article/20170502/OPINI ON/170429861/when-choosing-a-hospital-can-be-fatal.

New York City Department of Health and Mental Hygiene. (2020). Pregnancy-Associated Mortality New York City, 2011-2015. Retrieved June 6, 2020, from Long Island City, New York. https ://www1.nyc.gov/assets/doh/downloads/pdf/ms/pregnancy-assoc iated-mortality-report-2011-2015.pdf.

NYC Health. (2018). New York city standards for respectful care at birth. Retrieved June 6, 2020, from https://www1.nyc.gov/assets/ doh/downloads/pdf/ms/respectful-care-birth-brochure.pdf.

NYC Health. (2020a). COVID-19: Data. Retrieved June 6, 2020, from https://www1.nyc.gov/site/doh/covid/covid-19-data.page.

NYC Health. (2020b). COVID-19: Prevention and groups at higher risk. Retrieved June 6, 2020, from https://www1.nyc.gov/site/doh/ covid/covid-19-prevention-and-care.page

NYC Health. (2020c). Health Department launches the NYC standards for respectful care at birth. Retrieved June 6, 2020, from https:// www1.nyc.gov/site/doh/about/press/pr2018/pr098-18.page.

Trust for America's Health. (2020). The impact of chronic underfunding of America's public health system: Trends, risks, and recommendations, 2020. Retrieved July 3, 2020, from https://www.tfah. org/report-details/publichealthfunding2020/.

Publisher's Note Springer Nature remains neutral with regard to jurisdictional claims in published maps and institutional affiliations. 